\title{
Use of cephalosporins in patients with immediate penicillin hypersensitivity: cross-reactivity revisited
}

\author{
QU Lee *
}

\section{A B S T R A C T}

A $10 \%$ cross-reactivity rate is commonly cited between penicillins and cephalosporins. However, this figure originated from studies in the 1960s and 1970s which included first-generation cephalosporins with similar side-chains to penicillins. Cephalosporins were frequently contaminated by trace amount of penicillins at that time. The sidechain hypothesis for beta-lactam hypersensitivity is supported by abundant scientific evidence. Newer generations of cephalosporins possess side-chains that are dissimilar to those of penicillins, leading to low cross-reactivity. In the assessment of crossreactivity between penicillins and cephalosporins, one has to take into account the background betalactam hypersensitivity, which occurs in up to $10 \%$ of patients. Cross-reactivity based on skin testing or in-vitro test occurs in up to $50 \%$ and $69 \%$ of cases, respectively. Clinical reactivity and drug challenge test suggest an average cross-reactivity rate of only $4.3 \%$. For third- and fourth-generation cephalosporins, the rate is probably less than $1 \%$. Recent international guidelines are in keeping with a low cross-reactivity rate. Despite that, the medical community in Hong Kong remains unnecessarily skeptical. Use of cephalosporins in patients with penicillin hypersensitivity begins with detailed history and physical examination. Clinicians can choose a cephalosporin with a different side-chain. Skin test for penicillin is not predictive of cephalosporin hypersensitivity, while cephalosporin skin test is not sensitive. Drug provocation test by experienced personnel remains the best way to exclude or confirm the diagnosis of drug hypersensitivity and to find a safe alternative for future use. A personalised approach to cross-reactivity is advocated.

\section{Hong Kong Med J 2014;20:428-36}

DOI: $10.12809 / \mathrm{hkmj} 144327$

QU Lee * MB, ChB, FHKAM (Paediatrics)

Department of Paediatrics and Adolescent Medicine, Princess Margaret Hospital, Laichikok, Hong Kong

* Corresponding author: leequnui@gmail.com

\section{The ten per cent myth about beta- lactam cross-reactivity}

Penicillins and cephalosporins are two groups of widely prescribed antibiotics. They belong to the class of beta-lactam (BL) antibiotics because both possess the same BL nucleus. Allergic reactions are common side-effects of BL antibiotics. Studies in the 1960s and 1970s frequently estimated $10 \%$ crossreactivity between penicillins and cephalosporins. ${ }^{1,2}$ However, at least two recent reviews showed much lower cross-reactivity. ${ }^{3,4}$ Notably, cross-reactivity is higher between penicillins and first- and secondgeneration cephalosporins compared with thirdand fourth-generation cephalosporins. ${ }^{5}$ The latter two groups are considered safe alternatives for patients with penicillin hypersensitivity. ${ }^{6}$ The $10 \%$ cross-reactivity rate has recently been questioned as a medical myth. ${ }^{4,7}$ Yet until 2005, an influential drug reference such as the British National Formulary (BNF) abided by the "10\% rule". Faced with such recommendation, an ordinary physician naturally avoids all $\mathrm{BL}$ antibiotics in patients with a history suggestive of penicillin hypersensitivity. ${ }^{9}$ The implications are far-reaching as physicians often resort to expensive, broad-spectrum antibiotics, which may induce antibiotic resistance by selecting out resistant organisms. ${ }^{10}$ In order to minimise unnecessary exposure to expensive broad-spectrum antibiotics with higher toxicities and to preserve patients' right to receive commonly prescribed antibiotics, a better understanding of BL crossreactivity is needed. In the following discussion, the author will review the use of cephalosporins in patients with immediate hypersensitivity to penicillins. Mechanism and epidemiology of crossreactivity will be discussed, followed by a suggestion for a pragmatic approach.

By definition, 'cross-reaction' between two substances is "the interaction of an antigen with an antibody formed against a different antigen with which the first antigen shares identical or closely related antigenic determinants". ${ }^{11}$ Hence, antigenic similarity forms the basis of cross-reactivity. Public hospitals often suggest avoiding all cephalosporins indiscriminately for patients with penicillin 
hypersensitivity, as exemplified by a recent antibiotic guideline. $^{12}$ What remains unsettled is how far the $\mathrm{BL}$ nucleus also acts as a common antigenic determinant. In other words, does structural similarity in the drug nucleus translate into clinically relevant allergic reaction?

\section{Mechanism of beta-lactam hypersensitivity}

The BL nucleus is probably the only structure common to penicillins and cephalosporins. What differentiates between them is that penicillins possess a 5-membered thiazolidine ring attached to the $\mathrm{BL}$ nucleus while cephalosporins have a 6-membered dihydrothiazine ring. Secondly, while penicillins have a single 6-positioned side-chain, cephalosporins have a 3-positioned as well as a 7-positioned side-chain. ${ }^{3}$

When a BL antibiotic is absorbed into the body, the BL nucleus undergoes spontaneous opening. Covalent bonding between the drug and endogenous protein results in a hapten-protein conjugate. In case of penicillins, stable protein conjugates formed include penicilloyl (major) determinants and other minor determinants. ${ }^{13}$ For cephalosporin, however, haptenic determinants are less clear. ${ }^{14}$ Once inside the body, cephalosporins undergo rapid fragmentation of the BL nucleus and dihydrothiazine rings. The resulting unstable metabolites do not allow haptenisation of proteins. ${ }^{15}$ In subjects with BL hypersensitivity, the hapten-protein conjugate has the capability to activate T-cells and the ensuing B-cell response. Specific immunoglobulin (Ig) E antibodies produced by B-cells become attached to the surface of effector cells such as mast cells and basophils. Subsequent exposure to the same drug induces formation of hapten-protein conjugates. Immediate hypersensitivity is the result of crosslinking of adjacent surface IgE molecules by the hapten-protein conjugates that culminates in rapid degranulation of preformed inflammatory mediators such as histamine and tryptase. ${ }^{16}$

\section{Mechanism of cross-reactivity and the side-chain hypothesis}

Early cephalosporins before 1980s were contaminated with trace amounts of penicillin during the manufacturing process by the cephalosporium mould. That partly accounted for the higher cross-reactivity rate between penicillins and first-generation cephalosporins. ${ }^{14}$ Crossreactivity within penicillins is based on common antigenic determinants. Antibody binding against basic structures such as BL ring or penicilloyl frequently results in higher cross-reactivity rate. More complex motifs, such as side-chains found only in certain sub-groups, are associated with

\section{青徽素過敏性患者使用頭孢菌素類： 再談交叉反應 \\ 李君宇}

青徽素類和頭狍菌素之間普遍被援引存在 $10 \%$ 的交叉過敏反應率。不 過, 這個數字起源於二十世紀六、七十年代有關具有類似側鏈的青徽 素及第一代頭狍菌素的研究。當代的頭孢菌素經常被微量的青徽素所 污染。 $\beta$-內酰胺類過敏性側鏈假説經由豐富的科學證據支持。較新一 代的頭孢菌素具有與青徽素不同的側鏈, 因此, 交叉反應性較低。在 評估青徽素和頭孢菌素之間的交叉反應性時, 必須考慮到背景 $\beta$-內酰 胺類過敏症, 其發病率可高達 $10 \%$ 。根據皮膚測試或體外測試的交叉 反應率分別高達 $50 \%$ 和 $69 \%$ 。臨床反應性和藥物激發試驗表明, 只有 4.3\%的平均交叉反應率。在第三、四代頭孢菌素而言, 交叉反應率大 概不到 $1 \%$ 。近期的國際指引亦符合低交叉反應率。儘管如此, 香港的 醫學界仍然抱有不必要的懷疑心態。為青徽素過敏患者處方頭狍菌素 時, 應首先詳細詢問病史和作體格檢查。醫生可以選擇具有不同側鏈 的頭孢菌素。青徽素皮膚試驗是不能預測頭孢菌素過敏的, 而頭孢菌 素皮膚試驗亦不夠靈敏。由經驗豐富的人員進行藥物激發是排除或確 認藥物過敏的最佳診斷方法, 也有助尋找另一個安全的替代品以備將 來之需。個人化的交叉反應進路應予以提倡。

lower cross-reactivity. An in-vitro experiment has identified two types of T-cells responsible for penicillin hypersensitivity. The restricted type is immunologically reactive against a combined penicilloyl and side-chain structure but exhibits little cross-reactivity with penicillins with different side-chains such as amoxicillin or ampicillin. The broad type does react against different penicillins, but not against cephalosporins. ${ }^{17}$

Epitopes (antibody-binding sites) on penicillin molecules may involve the BL nucleus, the thiazolidine ring, the side-chain or even the new antigenic determinant. Side-chain antigenic determinants account for $42 \%$ to $92 \%$ of the penicillin hypersensitivity. ${ }^{18,19}$ Epitopes on cephalosporin molecules are even more heterogeneous than penicillin, and involve the whole molecule. ${ }^{20} \mathrm{R} 1$ sidechain and $\mathrm{BL}$ fragment protein conjugates appear to be the major determinants of cephalosporin hypersensitivity. ${ }^{21}$ R2 side-chain makes little contribution to cephalosporin hypersensitivity, as it disappears when the BL ring is opened. ${ }^{22}$

Human studies have provided insight into the role of similarity in the R1 side-chains in causing $\mathrm{BL}$ cross-reactivity. ${ }^{15}$ For instance, the 2-amino2-phenylacetic acid side-chain in ampicillin is also present in first- or second-generation cephalosporins like cephalexin and cefaclor, respectively, but is absent in third- or fourth-generation cephalosporins. Similarly, the same 2-amino-2-(4-hydroxyphenyl) acetic acid side-chain is present in amoxicillin and cefadroxil but not in new generations of cephalosporins. ${ }^{16}$ In another study on selective 
amoxicillin hypersensitivity, Miranda et $\mathrm{al}^{23}$ have shown that oral challenge with cephadroxil, a firstgeneration cephalosporin that shared the same sidechain mentioned above, resulted in a cross-reactivity of $38 \%$. On the other hand, use of cefamandole, a second-generation cephalosporin with a different side-chain from amoxicillin and cephadroxil, did not result in any cross-reactivity. ${ }^{23}$ Notwithstanding, other authors do not accord with the side-chain hypothesis. ${ }^{24}$ Fine structure within the side-chain such as methylene group has also been suggested as an antigenic determinant common to penicillins and cephalosporins. ${ }^{25}$

\section{Background and co-existing drug hypersensitivity}

When dealing with potential cross-reactivity between penicillins and cephalosporins, one should take into account the background hypersensitivity rates in unselected population, which range between $0.7 \%$ and $10 \%$ for penicillins. ${ }^{26}$ However, among patients with a history of penicillin allergy, only $10 \%$ to $20 \%$ exhibit positive allergic reaction to skin test or challenge test. ${ }^{27,28} \mathrm{~A}$ non-urticarial, maculopapular skin rash is the most common allergic reaction with a frequency of $1 \%$ to $2 \%$. The frequency of anaphylaxis per penicillin course is $0.01 \%$ to $0.05 \%{ }^{29}$ Similarly, background hypersensitivity rates for cephalosporins range between $1 \%$ and $10 \%$, while anaphylaxis occurs in less than $0.02 \% .{ }^{30}$ In other words, patients with penicillin hypersensitivity may develop noncross-reacting allergic response to cephalosporins by coincidence. They are also at increased risk of non-BL hypersensitivity, with a reported rate of $16 \%$ to $23 \%{ }^{31,32}$ A caveat is that, as local prevalence data are lacking, epidemiological data can only be applied to the Hong Kong situation by extrapolation.

\section{Cross-reactivity based on cephalosporin skin testing}

Skin test is an in-vivo method used to diagnose IgE-mediated allergic response. Substantial crossreactivity in terms of skin testing exists between penicillins and first-generation cephalosporins. In the 1970s, Assem and Vickers ${ }^{33}$ studied 24 patients with penicillin hypersensitivity of which 11 (46\%) showed positive intradermal test to cephaloridine; however, this reaction was not observed in any of the patients without penicillin hypersensitivity. Dash ${ }^{2}$ studied 100 patients with clinical reaction to penicillin and demonstrated positive cephalosporin skin test in $11(11 \%)$ patients. However, seven $(9.3 \%)$ of 75 control subjects without penicillin hypersensitivity also tested positive. In another study in the 1980s, Sullivan et $\mathrm{al}^{34}$ recruited 74 patients with penicillin hypersensitivity confirmed by positive skin prick test (SPT). Of these, 38 (50\%) also exhibited a positive SPT to cephalothin, another first-generation cephalosporin. ${ }^{34}$ Audicana et $\mathrm{al}^{35}$ studied 34 patients allergic to penicillin and found that five (14\%) had positive skin test to cephalexin, a first-generation cephalosporin, but none to ceftazidime, a thirdgeneration cephalosporin. Romano et $\mathrm{al}^{36}$ studied 128 adult subjects with a history of immediate penicillin hypersensitivity; positive cephalosporin skin test was observed in $11 \%$ of them. Of the 128 subjects, 101 (94 skin test negative and 7 skin test positive for cephalosporins) who accepted the challenge could tolerate oral cefuroxime axetil and intramuscular ceftriaxone. ${ }^{36}$ Although controlled trial is not possible, the implication is that cephalosporins can be safely given to patients with a history of penicillin hypersensitivity but who have negative cephalosporin skin test.

\section{Cross-reactivity based on in-vitro tests}

Substantial in-vitro cross-reactivity also exists between penicillins and first-generation cephalosporins. In an early study in 1960s, Abraham et $\mathrm{al}^{37}$ were able to demonstrate haemagglutination antibody against cephalothin (titre of 1:8 or greater) in $22(69 \%)$ of 32 patients who had been given penicillin but denied a history of cephalothin therapy. A subsequent adsorption study using penicilloic acid-solid phase by Zhao et $\mathrm{al}^{25}$ further identified cross-reacting specific IgE antibodies against both benzylpenicillin and cephalothin. Recently, Liu et $\mathrm{al}^{38}$ employed radioallergosorbent test to identify specific IgE antibodies against penicillins and cephalosporins in 420 subjects with penicillin hypersensitivity; cross-reacting specific IgE antibodies occurred in $22.6 \%$ of the subjects. Specific cephalosporin IgE antibodies were present in $27.1 \%$ of those with specific penicillin IgE antibodies, compared with $14.6 \%$ in those without specific penicillin IgE antibodies. ${ }^{38}$ However, in the absence of cross-linking, demonstration of antibodies cannot be equated with clinical reactivity. ${ }^{2}$

\section{Clinical reaction to cephalosporins in patients with a history of penicillin hypersensitivity}

As skin test and in-vitro test are often inadequate for confirmation of cephalosporin hypersensitivity, one has to rely on a provocation test or the result of drug exposure. In an early review of 701 patients with a history of penicillin hypersensitivity, Petz ${ }^{39}$ reported an $8.1 \%$ reactivity rate to first- or secondgeneration cephalosporins, compared with $1.9 \%$ among those without penicillin hypersensitivity. In another cohort study in the 1980 s by Solley et al, ${ }^{40}$ 178 patients with a history of penicillin allergy were given cephalosporins. Positive reaction resulted in 
two patients, equivalent to a clinical cross-reactivity rate of $1.1 \% .^{40}$ Goodman et $\mathrm{al}^{41}$ reviewed the medical records of 413 patients with a self-reported history of penicillin allergy who underwent anaesthetic procedures that included antibiotic therapy. Only one patient $(0.24 \%)$ probably developed cross-reactivity to cephalexin, a first-generation cephalosporin. ${ }^{41}$ Despite the retrospective nature and the lack of confirmatory tests, the low clinical cross-reactivity is reassuring.

Fonacier et $\mathrm{al}^{42}$ reviewed 83 patients with penicillin hypersensitivity who were subsequently given cephalosporins. Seven (8.4\%) of them developed an adverse drug reaction. A definite history of penicillin hypersensitivity was found in six $(85.7 \%)$ of the seven patients. Eleven (13.3\%) patients with penicillin hypersensitivity also reported hypersensitivity reaction to other drugs such as non-BL antibiotics and codeine. Regarding the types of cephalosporin, clinical cross-reactivity rates between penicillin and first-, second-, third-, and fourth-generation cephalosporins are 4.6\%, $50 \%, 10.5 \%$ and $0 \%$, respectively. Small sample size and potential recall bias undermine the reliability of the study. The role of side-chain is highlighted by a 4-fold increase in the cross-reactivity rate between penicillins and cephalosporins with similar aminobenzyl ring side-chain.

In a large prospective study by AtanaskovićMarković et $\mathrm{al}^{43}$ that included 644 children with a history of hypersensitivity reaction to penicillins, rate of cross-reactivity to cephalosporins was $31.5 \%$. If the generations of cephalosporins were taken into account, the cross-reactivity rate with aminopenicillins differed by 100 -fold, ranging from $0.3 \%$ to $0.7 \%$ in third-generation cephalosporins to around $32.4 \%$ to $38.5 \%$ in first- or second-generation cephalosporins, respectively. This, again, illustrates the relevance of side-chain in cross-reactivity. An interesting corollary is that, in patients with negative skin test to penicillins or cephalosporins, $0 \%$ to $1.8 \%$ of patients showed positive drug challenge to the test drug. Hence the false-negative rate of skin test is quite low. On the other hand, as patients with positive skin test were not further challenged with drugs to confirm clinical hypersensitivity, the truepositive rate cannot be ascertained.

A 5 -year retrospective study by Apter et $\mathrm{al}^{32}$ reviewed 534810 patients in the United Kingdom who received a penicillin followed by cephalosporin of which $64 \%$ were tested with first-generation cephalosporins. The authors compared 3920 patients with allergy-like events (ALE) within 30 days of receiving penicillin with 530890 patients without ALE. Among 3920 patients with ALE after receiving penicillin, $1 \%$ cross-reacted with cephalosporins. The unadjusted risk ratios for ALE after the subsequent cephalosporin and sulphonamide challenges were
10.0 (95\% confidence interval $[\mathrm{CI}], 7.4-13.6)$ and 7.2 (95\% CI, 3.8-13.5), respectively, suggesting that patients allergic to penicillin may have an increased tendency for drug hypersensitivity via a mechanism other than cross-reactivity.

In another retrospective study, Daulat et $\mathrm{al}^{44}$ reviewed medical records of 606 patients with a history of penicillin allergy who were subsequently given a cephalosporin. Confirmatory penicillin skin testing was not reported. Clinical allergy occurred in only one patient given cefazolin, a firstgeneration cephalosporin. This is tantamount to a cross-reactivity rate of $0.165 \%$. As drug allergy was suspected from diagnostic coding only, true penicillin allergy, and hence cephalosporin crossreactivity, might have been higher.

In a landmark meta-analysis in 2007, Pichichero and Casey $^{15}$ reviewed nine studies that compared allergic reaction rate to cephalosporins in patients with or without penicillin allergy. Among 47284 patients with a history of penicillin allergy alone, the odds ratio (OR) for cephalosporin cross-reactivity in general was 2.63 (95\% CI, 2.11-3.28; $\mathrm{P}<0.00001)$. However, the increased cross-reactivity rate was mainly due to first-generation cephalosporins, as the corresponding ORs for first-, second-, and thirdgeneration cephalosporins were 4.79 (95\% CI, 3.716.17; $\mathrm{P}<0.00001$ ), 1.13 (95\% CI, 0.61-2.12; $\mathrm{P}=0.70$ ), and 0.45 (95\% CI, 0.18-1.13; $\mathrm{P}=0.09$ ), respectively. There was actually a trend towards decreased risk of cross-reactivity to third-generation cephalosporins, although the result did not reach statistical significance.

\section{Clinical reaction to cephalosporins in patients with penicillin hypersensitivity confirmed by investigations}

In a cohort study by Solley et $\mathrm{al}^{40}{ }^{40}$ none of the 27 patients with a history of penicillin allergy and a positive penicillin skin test developed clinical reactivity to cephalosporins. On the contrary, two of the 151 patients with allergic history but negative penicillin skin test reacted to cephalosporins, putting to doubt the value of penicillin skin test in predicting cross-reactivity to cephalosporins. ${ }^{40}$ In another small cohort study by Blanca et $\mathrm{al}^{45} 19$ patients with confirmed penicillin hypersensitivity were given parenteral cephamandole, a second-generation cephalosporin, followed by oral cephaloridine, a first-generation cephalosporin, if the former was tolerated. Two (10.5\%) of the 19 patients crossreacted with cephamandole while all the remaining 17 patients tolerated cephaloridine.

Sastre et $\mathrm{al}^{24}$ subjected 16 patients with selective amoxicillin hypersensitivity confirmed by skin test or drug challenge with cephadroxil, a 
first-generation cephalosporin. Two (12\%) were found to be cross-reactors. ${ }^{24}$ Novalbos et $\mathrm{al}^{46}$ recruited 41 patients with a history of penicillin hypersensitivity confirmed by either skin test or drug challenge. Patients were then challenged with three cephalosporins (cephazoline, cefuroxime and ceftriaxone) with side-chains which were different from that of penicillin. None of them cross-reacted with the cephalosporins. ${ }^{46}$ Hameed and Robinson ${ }^{47}$ recruited 158 patients with positive penicillin test. Seven $(4.4 \%)$ of them developed immediate hypersensitivity when given cephalosporins. None of the cephalosporins was from the third generation. ${ }^{47}$ There is a lack of published reports on anaphylactic reaction to cephalosporins in children with a history of anaphylaxis to penicillins, and only a few such reports in adults have been published. ${ }^{47}$

Macy and Burchette ${ }^{48}$ studied 83 patients with a history of adverse reaction to penicillin confirmed by skin test. Post-skin test exposure to cephalosporins in 42 resulted in adverse reaction in one, amounting to $2.4 \%$ cross-reactivity rate. The corresponding figure for non-BL was eight (10.8\%) out of 74, suggesting that in patients allergic to penicillin, cross-reactivity for non-BLs may be even higher than that for BLs. ${ }^{48}$ This study and the one by Apter et a ${ }^{32}$ have significant implications for practitioners who routinely employ non-BL antibiotics for patients with penicillin hypersensitivity.

In a preoperative assessment clinic, Park et $\mathrm{al}^{49}$ recruited 1072 patients with a history of BL allergy for penicillin skin testing. Among the 999 patients who underwent the skin test, 43 had a positive skin test for penicillin and three of those 43 eventually received cefazolin. None developed crossreactivity. ${ }^{49}$ Ahmed et $\mathrm{al}^{50}$ reviewed 173 children with a history of penicillin hypersensitivity, with or without a skin test, who underwent cephalosporin challenge. None among those with positive skin test

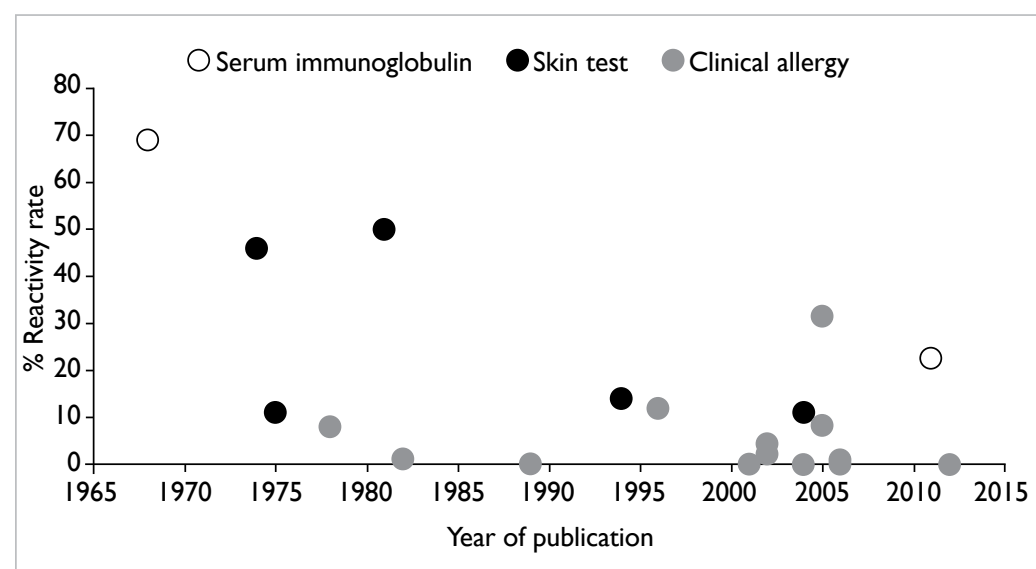

FIG I. Studies on cross-reactivity between penicillins and cephalosporins showed reactivity. However, one (0.7\%) of the 152 patients with negative skin test had an immediate allergic reaction after cephalexin, underscoring the lack of predictive power of the penicillin skin test. ${ }^{50}$

In a meta-analysis by Pichichero and Casey, ${ }^{15}$ 1831 patients with a history of penicillin allergy also received penicillin skin test. Compared with patients with negative skin test, the OR for crossreactivity to any cephalosporin for patients with positive results was 1.48 (95\% CI, 0.64-3.41; $\mathrm{P}=0.36$ ). Corresponding ORs for first-, second-, and thirdgeneration cephalosporins were 4.13 (95\% CI, 0.7024.51; $\mathrm{P}=0.11$ ), 1.33 (95\% CI, 0.32-5.52; $\mathrm{P}=0.69$ ), and 0.75 (95\% CI, 0.15-3.66; $\mathrm{P}=0.72$ ), respectively. ${ }^{15}$ There was a trend towards increased risk for firstgeneration cephalosporins, although the result did not reach statistical significance.

Studies on cephalosporin drug challenge in patients with a history of penicillin hypersensitivity have several inherent limitations. Firstly, retrospective studies are subjected to recall bias. Secondly, the so-called 'positive reaction' may include 'nocebo effects', ie untoward effects after administration of an inert substance, which may occur in around $27 \%$ of subjects. ${ }^{51}$ Thirdly, as most studies excluded patients with positive penicillin skin test, investigators had no way to tell whether these patients could actually tolerate cephalosporins. Lastly, most studies of cephalosporin challenge were performed in an open, uncontrolled manner. Patients with penicillin allergy who may have underlying multiple drug allergy syndrome will be missed in the absence of a control arm, such as non-BL group. ${ }^{52}$

\section{Ten per cent cross-reactivity: an over-estimation}

Review of published studies, as described above, shows that cross-reactivity between penicillins and cephalosporins, if restricted to clinical reaction or positive drug challenge, varies between $0 \%$ and $31.5 \%$ (Fig 1). Among the 14 studies that included a total of 6464 patients with penicillin hypersensitivity, 279 showed clinical reactivity or positive challenge to cephalosporins, resulting in an average crossreactivity rate of $4.32 \%$. Corresponding figures for patients with a history of penicillin allergy alone and those confirmed by investigations are $4.34 \%$ and $3.76 \%$, respectively. Studies reporting rates higher than $10 \%$ are mainly those involving first- or secondgeneration cephalosporins, especially when in-vitro or skin tests were employed. It must be emphasised that although cross-reactivity is substantial with firstgeneration cephalosporins (up to 32\%), it is less than $1 \%$ for third-and fourth-generation cephalosporins.

A probable reason for the low cross-reactivity stems from the fact that, despite having the same BL nucleus, penicillins and cephalosporins are immunologically different. If the BL nucleus is 
the common antigenic determinant, one should expect a very high cross-reactivity. However, this is not the case because the $\mathrm{BL}$ ring opens in the process of metabolism to form major or minor determinants. Secondly, newer generations of cephalosporin do not share similar side-chains with penicillins, hence cross-reactivity will, generally, not occur. Thirdly, among patients with alleged penicillin hypersensitivity, less than $10 \%$ show genuine hypersensitivity. The majority of cases may suffer from transient adverse reaction followed by subsequent tolerance to cephalosporins. ${ }^{7}$

Despite current recognition of the low crossreactivity rate, international guidelines are not unanimous in their recommendations regarding the use of cephalosporins in patients with penicillin hypersensitivity. A recent practice parameter from a Joint Task Force in the United States stated that "most patients with a history of penicillin allergy tolerate cephalosporins". ${ }^{10}$ If patients with positive penicillin skin test are given cephalosporins, around $2 \%$ may cross-react, including some with anaphylactic reactions. If a clinician chooses not to skin test a patient with a history of penicillin allergy but directly prescribe a cephalosporin, the chance of developing a reaction is probably less than $1 \%$. In treating otitis media in children with penicillin allergy, the American Academy of Pediatrics simply suggested prescribing, rather than avoiding, either second- or third-generation cephalosporins. ${ }^{53}$ Basing on dissimilarity in chemical structures, the Academy considered cross-reactivity between penicillin and second- or third-generation cephalosporins to be 'highly unlikely'.

A relatively conservative approach is adopted by the Infectious Diseases Society of America (IDSA). In the 2012 clinical practice guideline for bacterial rhinosinusitis, the IDSA recommended third-generation cephalosporins only for patients with non-type I penicillin allergy. Non-BL antibiotics were recommended for those with type I penicillin allergy. ${ }^{54}$ Even more conservative is the British Medical Association; in the 2014 edition, the BNF advised against using cephalosporins in patients with penicillin hypersensitivity. Nevertheless, if no other alternatives are available, third- and fourthgeneration cephalosporins can be used, albeit with caution. ${ }^{55}$

Skepticism still lingers within the medical community in Hong Kong. For instance, a recent public hospital antibiotic guideline does not differentiate between different generations of cephalosporins, but treats all cephalosporins as having the potential to cross-react with penicillins. ${ }^{56}$ The IMPACT guideline in Hong Kong has aptly pointed out a deeprooted preoccupation with cross-reactivity among the medical profession. The guideline suggests that "second, third and fourth generation cephalosporins have negligible cross-reactivity with penicillin". However, it also raises a common concern that contra-indications indicated in product inserts have resulted in "medico-legal implications when using cephalosporins in patients with penicillin allergy" ${ }^{57}$ This concern is understandable but unfounded, for two reasons. Firstly, a legal case appealed to the New Jersey Supreme Court in 1998 has come to the final decision that product inserts alone do not establish a standard of care. ${ }^{3}$ Secondly, a review of the inserts shows that, rather than contra-indicating the use of cephalosporins, pharmaceutical companies only issue words of caution in patients with penicillin allergy. ${ }^{58,59}$

\section{Pragmatic approach to cross- reactivity}

For patients with suspected penicillin hypersensitivity, one should begin with careful history and physical examination to establish the likelihood of adverse drug reaction. Clinicians will not do justice by simply avoiding all cephalosporins in patients with so-called penicillin hypersensitivity. Injudicious use of non-BL antibiotics without precaution is falsely reassuring and will expose patients with allergic tendency to further drug hypersensitivity.

Allergological investigations should preferably be done 4 to 6 weeks after resolution of adverse drug reaction. ${ }^{60}$ One should start from skin testing to confirm penicillin hypersensitivity. Ideally, skin test reagents should include penicilloyl polylysine (PPL) and minor determinant mixture (MDM). Unfortunately, the two major manufacturers, Allergopharma (Hamburg, Germany) and HollisterStier (Spokane, WA, US) ceased production of PPL and MDM in 2004. Although Diater (Madrid, Spain) has launched the production of PPL and MDM since 2003, the reagents have not gained widespread popularity in Hong Kong. ${ }^{61}$ Besides, diagnosis of selective reaction to a single $\mathrm{BL}$ requires a long algorithm, which begins testing with PPL and MDM, followed by the culprit drug. ${ }^{5}$ This may be tedious and time-consuming in daily clinical practice. For pragmatic purposes, it is often the culprit drug and/ or a potentially safe alternative that will be tested and prescribed. Non-irritating concentration of the culprit drug should be employed for skin testing. ${ }^{62}$

Patients with negative penicillin skin test may undergo supervised drug provocation test (DPT) of the culprit drug. ${ }^{3}$ The aim of DPT is to exclude or confirm the diagnosis of drug hypersensitivity and to find a safe alternative for future use. Drug provocation test generally has a high negative predictive value of $94 \%$ to $98 \%$. A caveat is that anaphylactic reactions can still occur among a few cross-reacting patients. Hence, DPT must be performed by experienced 


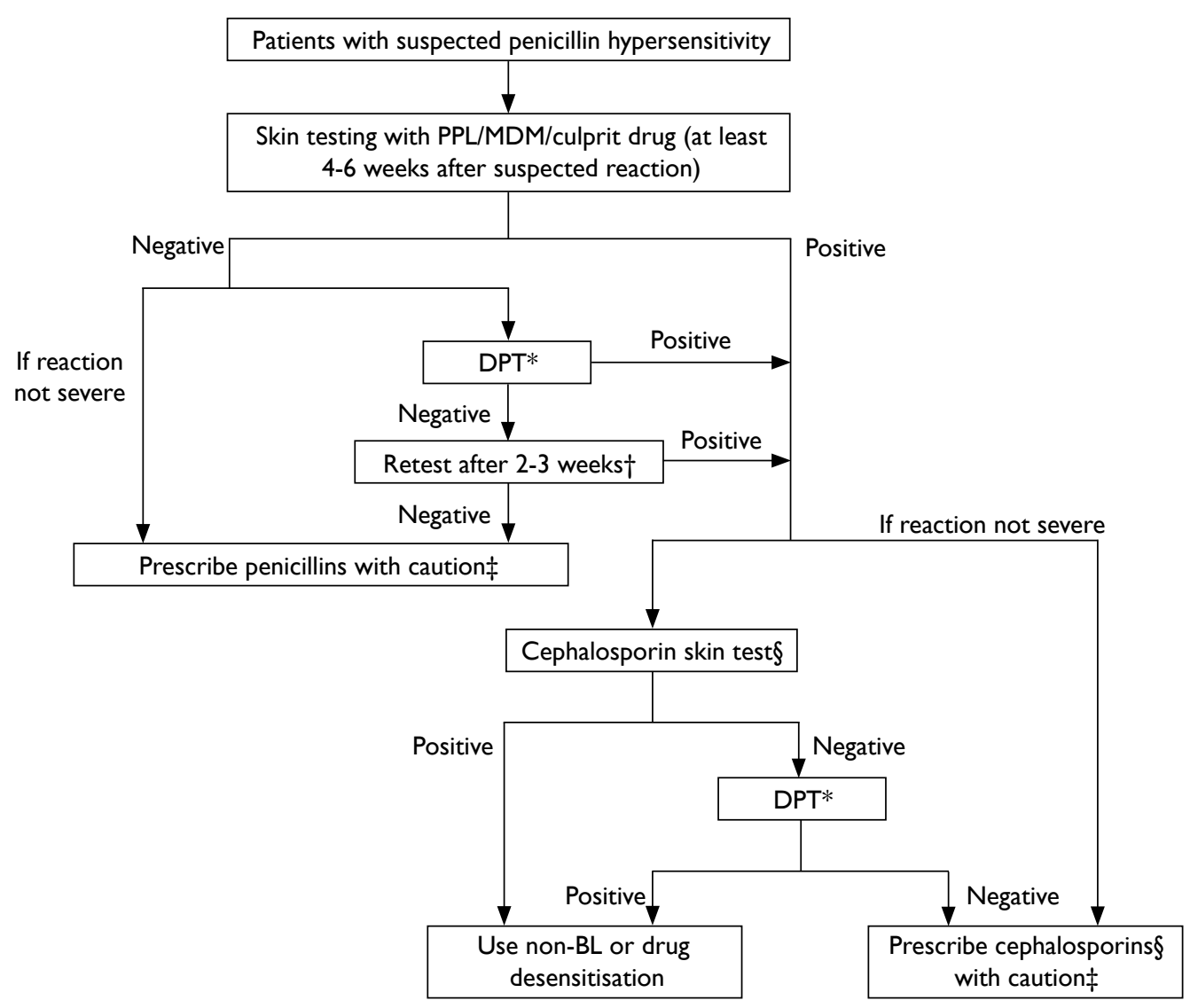

FIG 2. Suggested algorithm for investigation and management of suspected penicillin hypersensitivity

Abbreviations: DPT = drug provocation test; $M D M=$ minor determinant mixture; non-BL = non-beta-lactam; PPL = penicilloylpolylysine

* Contra-indicated if there is a history of severe cutaneous drug reaction or unstable medical conditions (controlled asthma, pregnancy, etc)

+ If there is a remote history or severe hypersensitivity

$\neq$ The first dose may be prescribed in the form of a DPT

$\S$ Use a cephalosporin with a different side-chain from the culprit drug

personnel in a setting with resuscitation facilities. ${ }^{60}$ Patients with remote or severe hypersensitivity may be re-tested 2 to 4 weeks later to exclude a small but possible risk of re-sensitisation after initial negative testing. Contra-indications to DPT include a history of severe cutaneous drug reactions (eg StevensJohnson syndrome or toxic epidermal necrolysis), severe anaphylaxis or certain medical conditions (eg uncontrolled asthma or pregnancy). ${ }^{63}$ In the absence of severe or recent immediate penicillin hypersensitivity, patients may choose to receive penicillin directly without skin testing. ${ }^{10}$ To further ensure drug safety, the first dose may be divided into incremental steps similar to DPT.

Patients who have a history of severe penicillin hypersensitivity, a positive penicillin skin test or DPT may resort to cephalosporins. However, a positive penicillin skin test does not predict cross-reactivity with cephalosporin. ${ }^{30,50}$ Clinicians may perform skin tests using a cephalosporin with a different side-chain to guide clinical use. ${ }^{10}$ Unfortunately, the diagnostic accuracy of cephalosporin skin test is difficult to establish. ${ }^{5}$ Studies generally have shown low sensitivity and positive predictive value. ${ }^{64,65}$ Nevertheless, skin test for BL hypersensitivity is still considered 'good' by the International Consensus in 2014. ${ }^{60}$ Patients with negative cephalosporin skin test should pass a DPT before finally receiving a cephalosporin. Patients who fail the DPT may be given a non-BL antibiotic or undergo desensitisation, if the cephalosporin is essential. ${ }^{60}$ A suggested algorithm for investigation and management of suspected immediate penicillin hypersensitivity is summarised in Figure 2. 


\section{Conclusion}

The available evidence to date does not support the notion of a $10 \%$ cross-reactivity rate between penicillins and cephalosporins. Above all, $10 \%$ is an oversimplified and indiscriminate generalisation of cross-reactivity. Scientific evidence supports the side-chain hypothesis and a low cross-reactivity rate. Clinicians should adopt a personalised approach towards BL cross-reactivity. Finally, future research on the local prevalence of BL hypersensitivity and cross-reactivity is needed.

\section{Declaration}

No conflicts of interests were declared by the author.

\section{References}

1. Petz LD, Fudenberg HH. Coombs-positive hemolytic anemia caused by penicillin administration. N Engl J Med 1966;274:171-8.

2. Dash $\mathrm{CH}$. Penicillin allergy and the cephalosporins. J Antimicrob Chemother 1975;1(3 Suppl):107-18.

3. DePestel DD, Benninger MS, Danziger L, et al. Cephalosporin use in treatment of patients with penicillin allergies. J Am Pharm Assoc (2003) 2008;48:530-40.

4. Campagna JD, Bond MC, Schabelman E, Hayes BD. The use of cephalosporins in penicillin-allergic patients: a literature review. J Emerg Med 2012;42:612-20.

5. Torres MJ, Blanca M, Fernandez J, et al. Diagnosis of immediate allergic reactions to beta-lactam antibiotics. Allergy 2003;58:961-72.

6. Prematta T, Shah S, Ishmael FT. Physician approaches to beta-lactam use in patients with penicillin hypersensitivity. Allergy Asthma Proc 2012;33:145-51.

7. Herbert ME, Brewster GS, Lanctot-Herbert M. Medical myth: ten percent of patients who are allergic to penicillin will have serious reactions if exposed to cephalosporins. West J Med 2000;172:341.

8. British Medical Association and the Royal Pharmaceutical Society of Great Britain. British National Formulary BNF 49 March 2005. London: BMJ Books; 2005.

9. Solensky R, Earl HS, Gruchalla RS. Clinical approach to penicillin-allergic patients: a survey. Ann Allergy Asthma Immunol 2000;84:329-33.

10. Joint Task Force on Practice Parameters; American Academy of Allergy, Asthma and Immunology; American College of Allergy, Asthma and Immunology; Joint Council of Allergy, Asthma and Immunology. Drug allergy: an updated practice parameter. Ann Allergy Asthma Immunol 2010;105:259-73.

11. Cross reaction. In: Anderson DM, editor. Dorland's illustrated medical dictionary. 31st ed. Philadelphia: W.B. Saunders; 2007.

12. Kowloon West Cluster Antibiotic Subcommittee. KWC Antimicrobial Therapy Guide 2012, Second Edition [cited 2014 June 5]. Available from: https://gateway.ha.org. hk/f5-w-687474703a2f2f706d682e686f6d65\$\$sites/ $\mathrm{mg} /$ General/KWC\%20Antimicrobial\%20Thearpy\%20 Guide\%202012.pdf. Accessed Jun 2014.

13. Park B, Sanderson J, Naisbitt D. Drugs as haptens, antigens, and immunogens. In: Pichler WJ, editor. Drug hypersensitivity. Basel: Karger; 2007: 55-65.

14. Kelkar PS, Li JT. Cephalosporin allergy. N Engl J Med 2001;345:804-9.

15. Pichichero ME, Casey JR. Safe use of selected cephalosporins in penicillin-allergic patients: a metaanalysis. Otolaryngol Head Neck Surg 2007;136:340-7.

16. Torres M, Mayorga C, Blanca M. Urticaria and anaphylaxis due to betalactams (penicillins and cephalosporins). In: Pichler WJ, editor. Drug hypersensitivity. Basel: Karger; 2007: 190-203.

17. Mauri-Hellweg D, Zanni M, Frei E, et al. Cross-reactivity of $\mathrm{T}$ cell lines and clones to beta-lactam antibiotics. J Immunol 1996;157:1071-9.

18. Mayorga C, Obispo T, Jimeno L, et al. Epitope mapping of beta-lactam antibiotics with the use of monoclonal antibodies. Toxicology 1995;97:225-34.

19. Torres MJ, Romano A, Mayorga C, et al. Diagnostic evaluation of a large group of patients with immediate allergy to penicillins: the role of skin testing. Allergy 2001;56:850-6.

20. Pham NH, Baldo BA. beta-Lactam drug allergens: fine structural recognition patterns of cephalosporin-reactive IgE antibodies. J Mol Recognit 1996;9:287-96.

21. Sánchez-Sancho F, Perez-Inestrosa E, Suau R, et al. Synthesis, characterization and immunochemical evaluation of cephalosporin antigenic determinants. J Mol Recognit 2003;16:148-56.

22. Blanca M, Romano A, Torres MJ, et al. Update on the evaluation of hypersensitivity reactions to betalactams. Allergy 2009;64:183-93.

23. Miranda A, Blanca M, Vega JM, et al. Cross-reactivity between a penicillin and a cephalosporin with the same side chain. J Allergy Clin Immunol 1996;98:671-7.

24. Sastre J, Quijano LD, Novalbos A, et al. Clinical crossreactivity between amoxicillin and cephadroxil in patients allergic to amoxicillin and with good tolerance of penicillin. Allergy 1996;51:383-6.

25. Zhao Z, Baldo BA, Rimmer J. beta-Lactam allergenic determinants: fine structural recognition of a crossreacting determinant on benzylpenicillin and cephalothin. Clin Exp Allergy 2002;32:1644-50.

26. Idsoe O, Guthe T, Willcox RR, de Weck AL. Nature and extent of penicillin side-reactions, with particular reference to fatalities from anaphylactic shock. Bull World Health Organ 1968;38:159-88.

27. Graff-Lonnevig V, Hedlin G, Lindfors A. Penicillin allergy - a rare paediatric condition? Arch Dis Child 1988;63:1342-6.

28. Park MA, Li JT. Diagnosis and management of penicillin allergy. Mayo Clin Proc 2005;80:405-10.

29. Shepherd GM. Allergy to $\beta$-lactam antibiotics. Immunol Allergy Clin N Am 1991;11:611-33.

30. Annè S, Reisman RE. Risk of administering cephalosporin antibiotics to patients with histories of penicillin allergy. Ann Allergy Asthma Immunol 1995;74:167-70.

31. Khoury L, Warrington R. The multiple drug allergy syndrome: a matched-control retrospective study in patients allergic to penicillin. J Allergy Clin Immunol 1996;98:462-4.

32. Apter AJ, Kinman JL, Bilker WB, et al. Is there crossreactivity between penicillins and cephalosporins? Am J Med 2006;119:354.e11-9.

33. Assem ES, Vickers MR. Tests for penicillin allergy in man. 
II. The immunological cross-reaction between penicillins and cephalosporins. Immunology 1974;27:255-69.

34. Sullivan TJ, Wedner HJ, Shatz GS, Yecies LD, Parker CW. Skin testing to detect penicillin allergy. J Allergy Clin Immunol 1981;68:171-80.

35. Audicana M, Bernaola G, Urrutia I, et al. Allergic reactions to betalactams: studies in a group of patients allergic to penicillin and evaluation of cross-reactivity with cephalosporin. Allergy 1994;49:108-13.

36. Romano A, Guéant-Rodriguez RM, Viola M, Pettinato R, Guéant JL. Cross-reactivity and tolerability of cephalosporins in patients with immediate hypersensitivity to penicillins. Ann Intern Med 2004;141:16-22.

37. Abraham GN, Petz LD, Fudenberg HH. Immunohaematological cross-allergenicity between penicillin and cephalothin in humans. Clin Exp Immunol 1968;3:343-57.

38. Liu XD, Gao N, Qiao HL. Cephalosporin and penicillin cross-reactivity in patients allergic to penicillins. Int J Clin Pharmacol Ther 2011;49:206-16.

39. Petz LD. Immunologic cross-reactivity between penicillins and cephalosporins: a review. J Infect Dis 1978;137 Suppl:S74-S79.

40. Solley GO, Gleich GJ, Van Dellen RG. Penicillin allergy: clinical experience with a battery of skin-test reagents. J Allergy Clin Immunol 1982;69:238-44.

41. Goodman EJ, Morgan MJ, Johnson PA, Nichols BA, Denk $\mathrm{N}$, Gold BB. Cephalosporins can be given to penicillinallergic patients who do not exhibit an anaphylactic response. J Clin Anesth 2001;13:561-4.

42. Fonacier L, Hirschberg R, Gerson S. Adverse drug reactions to a cephalosporins in hospitalized patients with a history of penicillin allergy. Allergy Asthma Proc 2005;26:135-41.

43. Atanasković-Marković M, Velicković TC, GavrovićJankulović M, Vucković O, Nestorović B. Immediate allergic reactions to cephalosporins and penicillins and their cross-reactivity in children. Pediatr Allergy Immunol 2005;16:341-7.

44. Daulat S, Solensky R, Earl HS, Casey W, Gruchalla RS. Safety of cephalosporin administration to patients with histories of penicillin allergy. J Allergy Clin Immunol 2004;113:1220-2.

45. Blanca M, Fernandez J, Miranda A, et al. Cross-reactivity between penicillins and cephalosporins: clinical and immunologic studies. J Allergy Clin Immunol 1989;83:3815.

46. Novalbos A, Sastre J, Cuesta J, et al. Lack of allergic crossreactivity to cephalosporins among patients allergic to penicillins. Clin Exp Allergy 2001;31:438-43.

47. Hameed TK, Robinson JL. Review of the use of cephalosporins in children with anaphylactic reactions from penicillins. Can J Infect Dis 2002;13:253-8.

48. Macy E, Burchette RJ. Oral antibiotic adverse reactions after penicillin skin testing: multi-year follow-up. Allergy 2002;57:1151-8.

49. Park M, Markus P, Matesic D, Li JT. Safety and effectiveness of a preoperative allergy clinic in decreasing vancomycin use in patients with a history of penicillin allergy. Ann
Allergy Asthma Immunol 2006;97:681-7.

50. Ahmed KA, Fox SJ, Frigas E, Park MA. Clinical outcome in the use of cephalosporins in pediatric patients with a history of penicillin allergy. Int Arch Allergy Immunol 2012;158:405-10.

51. Liccardi G, Senna G, Russo M, et al. Evaluation of the nocebo effect during oral challenge in patients with adverse drug reactions. J Investig Allergol Clin Immunol 2004;14:104-7.

52. American Academy of Allergy Asthma \& Immunology. Work group report: cephalosporin administration to patients with a history of penicillin allergy May, 2009 [cited 2014 April 6]. Available from: https://www.aaaai.org/Aaaai/ media/MediaLibrary/PDF\%20Documents/Practice\%20 and\%20Parameters/Cephalosporin-administration-2009. pdf. Accessed Apr 2014.

53. Lieberthal AS, Carroll AE, Chonmaitree T, et al. The diagnosis and management of acute otitis media. Pediatrics 2013;131:e964-99.

54. Chow AW, Benninger MS, Brook I, et al. IDSA clinical practice guideline for acute bacterial rhinosinusitis in children and adults. Clin Infect Dis 2012;54:e72-e112.

55. British Medical Association and the Royal Pharmaceutical Society of Great Britain. British National Formulary BNF 66 September 2013. London: BMJ Books; 2014.

56. Ching B. Hospital Authority guideline on known drug allergy checking. Hong Kong: Hospital Authority; 2013.

57. Reducing bacterial resistance with IMPACT-Interhospital Multi-disciplinary Programme on Antimicrobial ChemoTherapy. 4th ed. Hong Kong: Centre for Health Protection; 2012.

58. Ceftriaxone for Injection, USP [package insert] Lake Forest, IL: Hospira; [updated Dec 2010; cited 2014 June 22]. Available from: http://www.hospira.com/Images/EN2726_32-91495_1.pdf. Accessed Jun 2014.

59. Cefotaxime for Injection, USP [package insert] Bridgewater, NJ: Sanofi; [updated Feb 2014; cited 2014 June 22]. Available from: http://products.sanofi.us/claforan/ claforan.pdf. Accessed Jun 2014.

60. Demoly P, Adkinson NF, Brockow K, et al. International Consensus on drug allergy. Allergy 2014;69:420-37.

61. Romano A, Viola M, Bousquet PJ, et al. A comparison of the performance of two penicillin reagent kits in the diagnosis of beta-lactam hypersensitivity. Allergy 2007;62:53-8.

62. Brockow K, Garvey LH, Aberer W, et al. Skin test concentrations for systemically administered drugs-an ENDA/EAACI Drug Allergy Interest Group position paper. Allergy 2013;68:702-12.

63. Aberer W, Bircher A, Romano A, et al. Drug provocation testing in the diagnosis of drug hypersensitivity reactions: general considerations. Allergy 2003;58:854-63.

64. Romano A, Gaeta F, Valluzzi RL, Alonzi C, Viola M, Bousquet PJ. Diagnosing hypersensitivity reactions to cephalosporins in children. Pediatrics 2008;122:521-7.

65. Yoon SY, Park SY, Kim S, et al. Validation of the cephalosporin intradermal skin test for predicting immediate hypersensitivity: a prospective study with drug challenge. Allergy 2013;68:938-44. 